\title{
Costs involved in using a cochlear implant in South Africa
}

\author{
G Kerr, S Tuomi, A Müller \\ Division of Speech Language and Hearing Therapy, Stellenbosch University \\ Gillian Kerr \\ Seppo Tuomi \\ Alida Müller
}

Corresponding author: G Kerr (gill.kerr@westerncape.gov.za)

Cochlear implantation is an expensive but effective lifelong intervention for individuals with a severe-to-profound hearing loss. The primary aim of this study was to survey the short- and long-term costs of cochlear implantation. Individuals $(N=154)$ using cochlear implants obtained from the University of Stellenbosch-Tygerberg Hospital Cochlear Implant Unit in Cape Town, South Africa were surveyed using a questionnaire and patient record review. The questionnaire used a combination of closed and open-ended questions to gather both quantitative and qualitative information. Costs were categorised as short- and long-term costs. All costs were converted to constant rands (June 2010) using the Consumer Price Index to allow for comparison in real terms over time. In the first 10 years of implantation the average estimated costs incurred by adults totalled R379 626, and by children R455 225. The initial purchase of the implant system was the most substantial cost, followed by upgrading of the processor. Travel and accommodation costs peaked in the first 2 years. On average the participants spent R2 550 per year on batteries and spares. Rehabilitation for children cost an average of R7 200. Insurance costs averaged R4 040 per year, and processor repairs R3 000 each. In addition to the upfront expense of obtaining the cochlear implant system, individuals using a cochlear implant in South Africa should be prepared for the long-term costs of maintenance, accessing the unit, support services and additional costs associated with use. Knowledge of these costs is important to ensure that individuals are successful users of their cochlear implants in the long term.

Keywords: South Africa, cochlear implants, long-term use, costs for individuals

S Afr J CD 2012;59(1):16-26. DOI:10.7196/SAJCD.117

Since the introduction of multichannel cochlear implants in 1984 (Eisen, 2009), the potential hearing and speech outcomes of individuals with a severe-to-profound hearing loss have been revolutionised (McCormick, 2003; Niparko, 2009; Peters, Wyss \& Manrique, 2010). The effectiveness of cochlear implants in providing increased sound perception for this population is well documented. They result in improved auditory performance and speech perception for adults and children, with benefits extending to improvements in education, occupation and quality of life (Carpenter, 2009; Chute \& Nevins, 2006; Ramsden et al., 2012). Cochlear implants have become the treatment of choice for many individuals with severe or profound sensorineural hearing loss (Chute \& Nevins, 2006; Carpenter, 2009).

Cochlear implants are also cost-effective (Lin, Niparko \& Francis, 2009; O’Neill, 2002; Palmer, Niparko, Wyatt, Rothman \& DeLissovoy, 1997; Sach, 2002; Wyatt, Niparko, Rothman \& DeLissovoy, 1995). Despite this, they are used in low volumes (Khan, Mukhtar, Safeed \& Ramsden, 2007). As of December 2010, approximately 219000 individuals had received cochlear implants worldwide (NIDCD, 2011). The relatively low volume used is probably due to the high cost of the implant system (retailing in the $\$ 30000$ range), as well as the costs of hospital admission, surgical fees and post-implant rehabilitation. These expenses keep cochlear implants out of reach for many individuals with profound hearing loss, especially in poor and socio-economically developing countries (Glasscock, 2011). Without access to such technology the potential choice of access to developing spoken language (congenital profound losses) or to retaining access to spoken language (acquired profound hearing loss) is denied for these individuals. Although some individuals with severe or profound hearing loss may choose to follow a manual communication system, without potential access to cochlear implants, such a choice may be forced upon others.

Obtaining a cochlear implant commits an individual to a lifetime use of such a device. In countries like South Africa, where implants are not provided by the National Department of Health $(\mathrm{NDoH})$, individuals using a cochlear implant need to have adequate finances to be able to access the rapidly developing technology for the rest of their lives. For the purpose of economic evaluation, the process and costs of cochlear implantation can be divided into assessment, implantation, rehabilitation and maintenance (Hutton \& Politi, 1995). In addition, the individual must be able to access a specialist facility, where cochlear implantation is offered. In South Africa, reaching one of the facilities in six main city centres could involve additional costs of travelling long distances.

Although the initial costs of surgery and the implant system are available, little information is available in South Africa about either the overall costs over time or individual cost categories. The high cost of the implant system itself frequently receives the primary focus, with less consideration given to the ongoing financial burden of using and maintaining the implant system, and of the rehabilitation.

\section{Previous cost studies}

Most studies have considered costs from the perspective of a thirdparty payer (e.g. medical aid or insurance) or society at large rather than from the perspective of the individual using the cochlear implant. Studies which have investigated costs incurred by individuals or their families include those conducted in the UK (Barton, Fortnum, Stacey \& Summerfield, 2006; Sach, Whynes, Archbold \& O’Donaghue, 2005), the USA (Cheng et al., 2000) and Canada (Fitzpatrick et al., 2006). Most of these studies have been in developed countries, where a number of the direct costs are not paid for by the individuals using the cochlear implant. In the UK, for example, the tax-funded National Health Service meets the costs of the entire cochlear implant service (Sach, Whynes, O'Neill, O'Donaghue \& Archbold, 2004). The individuals and their families carry no direct costs for the service.

In contrast, cochlear implants are mostly self-funded in many developing countries, necessitating consideration of a patient's financial resources to fund both the implant system and the subsequent rehabilitation at the outset of pre-assessment (Khan et al., 2007).

No previous cost studies related to cochlear implantation have been conducted in South Africa. Applying the results of one country's costs studies to other countries is difficult because of differences in healthcare systems, costs of services, and health and educational service delivery methods (Fitzpatrick et al., 2006). Each country's unique funding and economic situation needs to be considered. 


\section{The South African context}

In June 2010 South Africa had an estimated population of 49.99 million people (Statistics South Africa, 2010). The country has a dichotomised health system. Eighty-three per cent of the population is mainly reliant on the public health sector, which lacks sufficient systems, skills and resources to deliver healthcare services efficiently and operate health facilities optimally. This runs parallel with a well-resourced private health sector, which serves a minority of the population. Eight million (17\%) South Africans are covered by private medical schemes (Blecher, Kollipara, DeJager \& Zulu, 2011). Although the private-public differential reveals a narrowing trend in recent years, inequity in health access, quality of care and spending remain a major challenge. Despite South Africa spending around 8.6\% of gross domestic product on health, overall health outcomes of South Africans remain inadequate (Blecher et al., 2011).

The Ministry of Health has committed to the negotiated service delivery agreement (NSDA) (2010 - 2014), focusing on improving health outcomes by targeting four key outputs, viz. to increase life expectancy, decrease maternal and child mortality, combat HIV and AIDS and decrease the burden of disease from tuberculosis, and to strengthen the effectiveness of the health systems (Blecher et al., 2011). Against the backdrop of lifethreatening disease and a prioritisation towards primary healthcare, specialised rehabilitative approaches, such as cochlear implantation, essentially a quaternary level of care, are not seen as a priority for $\mathrm{NDoH}$ spending. It is also unlikely that they will become so in the foreseeable future. The costs of the procedure have to be met by the individuals who receive a cochlear implant and their families, who may, or may not, have access to some funding from a private medical aid.

The first multichannel cochlear implantation in South Africa took place at the Tygerberg Hospital-University of Stellenbosch Cochlear Implant Unit (hereafter referred to as the Tygerberg Hospital Cochlear Implant Unit) in November 1986. By June 2010 almost 1000 individuals had been implanted in the country (J. Wiegman, personal communication, 10 August 2010). Wagenfeld and Müller (1994), who pioneered the work in the field of cochlear implantation in South Africa, cautioned that the financial implications of lifetime maintenance of an implant, rather than the supply of the implant hardware itself, represent the biggest financial obstacle for individuals requiring and using cochlear implants. As more individuals continue to be implanted in the country, it is important to use the experience gained from 25 years of implantation to guide further intervention. It is necessary to be able to detail the long-term costs borne by the individuals receiving a cochlear implant, as well as to examine and anticipate their course over time. This information is needed to provide realistic guidance regarding the financial implications of implantation to individuals who are considering obtaining a cochlear implant. It is also needed to help guide individuals already using an implant and clinicians working in the field.

\section{Methodology}

Aims

The current study investigated the costs incurred by the existing population using a cochlear implant at the Tygerberg Hospital Cochlear Implant Unit. The aim of the study was to determine the short- and long-term costs of using a cochlear implant system for this population.

\section{Study design}

The study employed a non-experimental ex post facto research design (Bailey, 1997; Hegde, 2003). Individuals, who had received a cochlear implant at the Tygerberg Hospital Cochlear Implant Unit between November 1986 and March 2010, were surveyed by means of a questionnaire and examination of patient records. The survey contained two different types of questions designed to elicit different types of information from participants. Some questions tapped quantitative data, which were analysed using descriptive statistics. Other questions were open-ended, which allowed participants freedom to respond and include issues they thought important. The qualitative data yielded by these latter questions were subjected to theme analysis.

\section{Costs investigated}

The following costs were investigated:

\section{Short-term costs}

- Initial acquisition

- The implant system

Long-term costs

- Maintenance and use

- Upgrades of the processor

- Batteries

- Spare parts

- Repairs

- Travel and accommodation associated with visits to the implant unit

- Support services

- Rehabilitation for children

- Optional costs

- Insurance

- Hearing aid in non-implanted ear

- Personal frequency modulation (FM) system

In addition, the manner of funding and development of costs over time were monitored. Advice from participants to individuals considering using a cochlear implant in the future regarding costs was solicited and analysed.

The costs of radiological investigations, consultations with the ear nose and throat surgeon, surgery and hospitalisation were excluded from this study. These costs tend to be either covered by medical aids, for individuals accessing private healthcare, or are highly subsidised for state patients. Although expensive, these costs to the individuals themselves are often minimised. They are also more variable than the other costs investigated as they take place at a number of different facilities, and are not standardised, making comparisons difficult.

\section{Participants}

\section{Inclusion criteria}

The participants were required to be living in South Africa, and actively using their cochlear implants. They had to have been using their implant for a minimum period of 3 months at the time of the data collection, in order for them to be able to contribute meaningful information regarding the use of an implant, in addition to the purchase of it.

\section{Exclusion criteria}

Individuals who were implanted at other centres and subsequently managed at the Tygerberg Hospital Cochlear Implant Unit, those living in other countries, deceased individuals who had used a cochlear implant and those no longer using their cochlear implants were not included in the study.

\section{Sampling}

The population consisted of all the individuals who had received a cochlear implant from the Tygerberg Hospital Cochlear Implant Unit. The unit retains contact with all individuals implanted there, as they require lifelong audiological follow-up. It is a closed population where contact details are known for all, enabling access to all potential subjects. The questionnaire was sent to all individuals who met the inclusion criteria. Such probability sampling, which includes the entire defined study population, is considered the ideal random method of participant selection (Drummond, 1996; Hegde, 2003). All individuals had an equal chance of being included in the study. While the consent process in the study would have resulted in a degree of volunteerism, allowing each individual in the population an equal chance to participate reduced the potential effect of subject selection on the internal validity of the study (Bailey, 1997; Hegde, 2003).

\section{Description of participants}

Three hundred and ten individuals met the inclusion criteria and were sent the questionnaire. One hundred and sixty-four responded. Ten chose not to participate as a result of a variety of reasons including illness, time constraints and lack of records. One hundred and fifty-four individuals (50\%) participated. They consisted of 80 females and 74 males. 
Table 1. Monthly family income classification of participants

\begin{tabular}{llllll}
\hline Monthly family income & $\begin{array}{l}\text { Non-private }<\mathbf{6} \\
\text { years old }\end{array}$ & $\leq \mathbf{R 4} \mathbf{1 6 6}$ & $\mathbf{R 4} \mathbf{1 6 7 - \mathbf { R } 8 3 3 3}$ & $\geq \mathbf{R 8 ~ 3 3 4}$ & Medical aid \\
\hline Number of participants & $2(1 \%)$ & $27(18 \%)$ & $12(8 \%)$ & $17(11 \%)$ & $96(62 \%)$ \\
\hline
\end{tabular}

- Age at implantation. The average age of participants at implantation was 22 years, with a range of 6 months to 84 years. Eighty-two participants (53\%) were implanted as children (average age 4 years 5 months). A small number of participants (8) were implanted as teenagers (average age 15 years 9 months) and 64 (42\%) were implanted as adults (average age 45 years 2 months).

- Duration of implant use. The average duration of use of an implant was 7 years 4 months (range: 3 months to 22 years 7 months). Those implanted as children had, on average, used their implants for 8 years (range: 3 months to 21 years 2 months). The teenagers' average duration of use was 6 years 2 months (range: 1 year to 15 years 3 months). The adults had, on average, used their implants for 6 years 8 months (range: 4 months to 22 years 7 months).

\section{Income status}

The Tygerberg Hospital's Income Classification System was used to determine the current income status of the participants (see Table 1), which in turn determines the cost of visits to the implant unit. This classification is based on the patients' (or family's) monthly income, ranging from those earning least (unemployed, on grants or non-private children under 6 years) to those on medical aids. Ninety-six participants (62\%) were members of medical aids (charged the highest price for hospital visits, regardless of actual income level). Two participants were non-private children under 6 years of age, who qualified for free hospital appointments. The income distribution of the remaining 56 participants ranged from less than R4 166 to more than R8 334 per month.

\section{Ethics}

Permission to conduct the study was granted by the Health Research Ethics Committee of the Stellenbosch University and the Medical Superintendent of Tygerberg Hospital. Information and consent forms were distributed to all subjects. All participants returned a written signed consent form indicating their willingness to participate, and their understanding of the nature of the study. In the case of children, parents/caregivers were required to provide the written consent and complete the questionnaire.

\section{Data collection \\ Questionnaire}

A questionnaire (Appendix A), relevant for the South African context, was developed for the study. The questionnaire consisted of nine question areas. Eight asked for estimates of various costs and provided the participants with option ranges to choose from. The questions included: forced alternatives (yes/no type questions) and, where possible, presented closed set options for participants' responses. This structure was chosen to aid the speed and ease of completion for participants (Creative Research Systems, 2012; Drummond, 1996). One question (Question 8) was open-ended. This question probed advice which participants would give others regarding costs. The open-ended structure afforded participants an opportunity to respond more freely, and to include information which they felt was relevant to the question (Creative Research Systems, 2012; Drummond, 1996).

The participants were instructed to fill in as much information as possible. If they could not remember or did not have access to exact amounts they were asked to give estimated costs. Provision was also made for participants who did not remember a particular cost to indicate this on the questionnaire. In order to gain an idea of the different costs incurred at different time periods in the implantation process, the questionnaire requested the information according to time periods. These included: initial evaluation, 1 - 2 years, 3 - 5 years, 6 - 10 years, 11 - 15 years, 15 - 20 years and more than 20 years after receiving a cochlear implant. As the length of time the individuals had been using their cochlear implants varied, they completed only those time periods relevant to them.

Questions 1, 2 and 3 collected data related to visits to the cochlear implant unit. Question 4 probed information regarding the number of post-warranty repairs needed for the speech processor. Question 5 gathered information about the insurance of the speech processor. Question 6 investigated the purchase of a personal FM system and the costs involved. Question 7 extracted information about the use of a hearing aid in the contralateral ear (the ear not implanted), i.e. the purchase of the aid and monthly battery cost. Question 8 gave participants an opportunity to advise those considering an implant about costs and planning for costs, involved in obtaining and maintaining a cochlear implant based on their own experience. Question 9 examined rehabilitation costs for children (those who were implanted below the age of 13 years).

The content, as well as the phrasing of the questions, was carefully considered to ensure that only questions relevant to the study were asked in a way which did not lead the subject (Creative Research Systems, 2012; Drummond, 1996). The questionnaire was designed by the investigator, an audiologist with 10 years' experience working in cochlear implantation, and the founding co-ordinator of the unit, an audiologist with 25 years' experience working in the field of cochlear implantation in South Africa. The questions were judged to not include any cultural, racial, intelligence or language bias, which could have influenced the results. Care taken in the design of the questionnaire helped to ensure the internal validity of the study (Bailey, 1997; Creative Research Systems, 2012).

The questionnaire was developed in English and translated into Afrikaans, the two main languages spoken by individuals using a cochlear implant at the Tygerberg Hospital Cochlear Implant Unit. The accuracy of the translation was assessed by a bilingual EnglishAfrikaans speaking speech-language therapist and audiologist employed in an academic post at the Department of Speech-Language and Hearing Therapy, Stellenbosch University. The questionnaire was made available to participants in English or Afrikaans depending on their known preference.

Only the cost information for one cochlear implant per individual was collected. This was done in order to try to determine the minimum necessary costs which would need to be covered if an individual were to receive a cochlear implant. Currently most individuals still use one implant, though bilateral implantation is becoming the treatment of choice, especially for children (Johnston, Durieux-Smith, Angus, O'Connor \& Fitzpatrick, 2009; Ramsden et al., 2012; Summerfield, Lovett, Bellenger \& Batten, 2010). In this study, 30 participants (19\%) were bilaterally implanted.

\section{Pilot study of the questionnaire}

Prior to being used in the study the questionnaire was piloted on three individuals who used a cochlear implant, who were not included in the study, to ensure that participants would understand the questionnaire, and to help plan the procedures which would be used in the data collection (Creative Research Systems, 2012; Doehring, 2003). It was also used to determine whether the questions elicited the desired information and to evaluate whether the survey was too long or too short (Bailey, 1997). All three individuals indicated that they could follow all the instructions easily and that they understood all the questions as asked. Minor modifications to the reply format were made on the basis of their responses and suggestions. 


\section{Distribution of the questionnaires}

The questionnaires together with information sheets and consent forms were distributed to subjects via email, post or in person, when the individuals using a cochlear implant attended their follow-up appointments at the unit. Three hundred and ten questionnaires were distributed. One hundred and fifty-four completed questionnaires were returned, via email, fax, post (using a pre-paid envelope provided) or by hand directly to the unit. Email and telephone reminders were used to help improve the return rate of the questionnaires. The 50\% return rate obtained was considered acceptable as it was in keeping with the general findings of response rates to postal questionnaires, which are usually between 40\% and 60\% (Oppenheim (1996) cited in Drummond, 1996).

\section{Patient records}

The information supplied by the questionnaire was supplemented with and checked against information from patient and distributor records to increase the accuracy of data and to verify costs associated with implantation and maintenance. Where data were readily available in patient records, information was obtained from these sources rather than from the participants themselves to reduce possible potential inaccuracies related to participants' recall. Information from patient records was extracted from databases at the Tygerberg Hospital Cochlear Implant Unit and Southern ENT Pty (Ltd), the Tygerberg Hospital Income Classification System and the Tygerberg Hospital Cochlear Implant Unit Follow-up Protocol.

\section{Analysis of data}

The raw data were analysed to establish the relationships, trends and patterns of all the costs incurred by individuals using a cochlear implant, or their families, from the time of their initial assessment up to June 2010. All costs were converted into South African rand values as at June 2010, using the Consumer Price Index (CPI), so that they could be compared in real terms. Descriptive statistics were used. Means were used as a measure of central tendency and ranges as a measure of variability (Heffner, 2004; Stein \& Cutler, 1996).

Where ranges of costs were provided, the midpoint of the range was used in the calculations. Where the participant's responses fell into an open-ended interval (i.e. top limit unbound), the investigator estimated the most likely value to be used in the calculations. Very few responses were noted in the open-ended ranges, so this did not have a significant effect on the analysis.

The probability of occurrences of various costs in the different time periods following implantation was statistically determined, using contingency tables, based on the relative actual frequencies of occurrences for participants in the study. These included the occurrences of spares purchases, repairs and upgrades. Frequency distribution tables were constructed to analyse this information (Stein \& Cutler, 1996).

The responses to the open-ended Question 8 were subjected to a theme analysis (Aronson, 1994; Braun \& Clark, 2006). Responses were coded by participant number and analysed independently by the investigator and another experienced cochlear implant audiologist. The main themes were independently extracted from each participant's answer by the two analysers and compared. A $92 \%$ correlation between the two analysers' themes was obtained, indicating high inter-rater reliability (Doehring, 2003; Hegde, 2003).The few discrepancies were discussed to reach a consensus. The main themes were analysed for all participants to extract the most frequently occurring themes in the group and trends were extracted.

\section{Results and discussion \\ Total average costs}

The total average costs were calculated for the first 5 and 10 years post implantation (Table 2). Ten years represented the maximum time period for which complete records of spares and repair costs were available from the current South African distributor of the Nucleus ${ }^{\circledR}$ products used at the Tygerberg Hospital Cochlear Implant Unit. This grouping of costs allowed for the comparison of shorter- and longer-term costs incurred. These costs were calculated for private individuals living within $50 \mathrm{~km}$ of the unit. The costs of a hearing aid and an FM system were not included in these figures, as they are not costs essential to the use of a cochlear implant, or routinely encountered by all individuals using a cochlear implant. In this study only a third of the participants were using a hearing aid in the non-implanted ear, and only $15 \%$ had purchased an FM system.

As seen in Table 2, during the first 5-year period, the implant system cost was $74 \%$ of the total costs for children and $86 \%$ of the total costs for adults. During the first 10-year period these percentages dropped to $49 \%$ for children and $58 \%$ for adults, reflecting the increased costs over and above the initial purchase of the system itself encountered in the longer time period. The total costs for children (i.e. those implanted under 13 years) were significantly higher than for adults, mostly because of the additional rehabilitation costs (primarily speechlanguage therapy). Electrode programming costs for children were also higher as a result of the increased number of appointments needed, and on average spares costs were $40-50 \%$ greater for them. The difference in the costs between the first 5 and 10 years post implantation reflected the greater likelihood that repair and upgrade costs would occur in

Table 2.Total costs for first 5 and 10 years post implantation (June 2010)

\begin{tabular}{|c|c|c|c|c|}
\hline & 1 st 5 years (child) & 1 st 5 years (adult) & 1 st 10 years (child) & 1 st 10 years (adult) \\
\hline Implant system & R221 000 & R221 000 & R221 000 & R221 000 \\
\hline Batteries (CI) & R11 400 & R11 400 & R22 800 & R22 800 \\
\hline Spares & R1 849 & R738 & R2 795 & R1 444 \\
\hline Repairs & & & R2 950 & R2 950 \\
\hline Travel $(<50 \mathrm{~km})^{*}$ & R2 093 & R688 & R2 746 & R752 \\
\hline Electrode programming $\dagger$ & R5 240 & R3 930 & R6 550 & R5 240 \\
\hline Insurance & R20 220 & R20 200 & R40 440 & R40 440 \\
\hline Upgrade $\ddagger$ & & & R85 000 & R85 000 \\
\hline Total & R261 802 & R257 956 & R384 281 & R379 626 \\
\hline Speech therapy & R37 159 & & R70 944 & \\
\hline TOTAL & R298 961 & R257 956 & R455 225 & R379 626 \\
\hline
\end{tabular}

*Travel cost: cost per patient as estimated by participants.

$\dagger$ Average cost was used. This will be higher for younger children and lower for older children because of the increased number of appointments needed for younger individuals using a cochlear implant.

$\ddagger$ Upgrade price. 
the longer term. Findings from the study showed that, on average, participants upgraded their processor after 7 years of using their cochlear implant, and had their processor repaired once during the first 10 years of use, usually after at least 6 years of use. Individuals using a cochlear implant who lived further than $50 \mathrm{~km}$ from the unit, bore greater travel costs than those indicated in Table 2 and may also have had additional accommodation costs.

\section{Initial acquisition: implant system costs \\ Cochlear implant system costs over time}

The costs of the cochlear implant system from November 1986 to June 2010 are shown in Figure 1. All costs are in constant rands, as at June 2010. The cost of the implant system is the same for children and adults. The cochlear implant system was the greatest single cost involved in the implantation process. This result was similar to the findings in a recent French study, which also reported the cost of the device as the main cost in implantation (Molinier, Bocquet, Bongard \& Frayesse, 2009). In that study the cost of the device represented $64.4 \%$ and $68.8 \%$ of the total cost for children and adults respectively. This was lower than that noted for participants in this study during the first 5 years, and higher than that noted for participants during the first 10 years. Figure 1 shows the rising trend for the average system cost over the 24-year period, with a peak in average cost occurring between 2001 and 2005. The highest and lowest average costs varied by almost R100 000. The average cost of implants increased steadily from R152 026 in the earliest period to R246 589 during the 2001 - 2005 period, with a decline in the latest period. The average implant system in the most recent time period (2006 - 2010) cost almost R55 000 (R54 950) more than in the earliest time period (1986 - 1990). As the implant systems are manufactured outside of South Africa and imported for use, a major reason for their cost fluctuations and increase may be exchange rate changes.

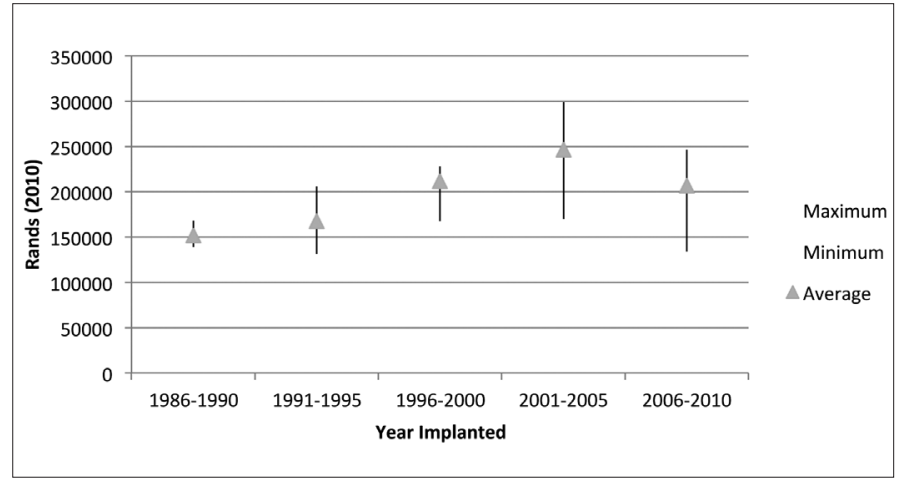

Fig. 1. Cochlear implant system costs between November 1986 and June 2010.

\section{Funding of implant systems}

Although the cochlear implant system was the greatest single cost in the implantation process, the amount which participants themselves had to pay varied. Figure 2 shows the sources participants used to fund their implant systems. Seventy per cent of the participants $(35 \%+34 \%+1 \%)$ were members of a medical aid at the time they were implanted. There was considerable variation in the medical aids' contribution towards the cost of the implant system. Half had the system fully funded by their medical aid while the other half received only partial funding and had to pay from $5 \%$ to $95 \%$ of the cost. The average partial contribution from the medical aids was $50 \%$ of the system cost.

Thirty per cent of the participants were not members of a medical aid when they were implanted. Twelve per cent of these individuals had to fully fund the system themselves. Another $12 \%$ were fully assisted by sponsors. Six per cent of the participants funded their implant system using a combination of their own funds and those from a sponsor.

\section{Maintenance costs Upgrades}

The cost of upgrading the sound processor was the second highest cost involved, adding up to almost $40 \%$ of the initial system cost (R85 000 at June 2010). On average the participants had upgraded every 7 years

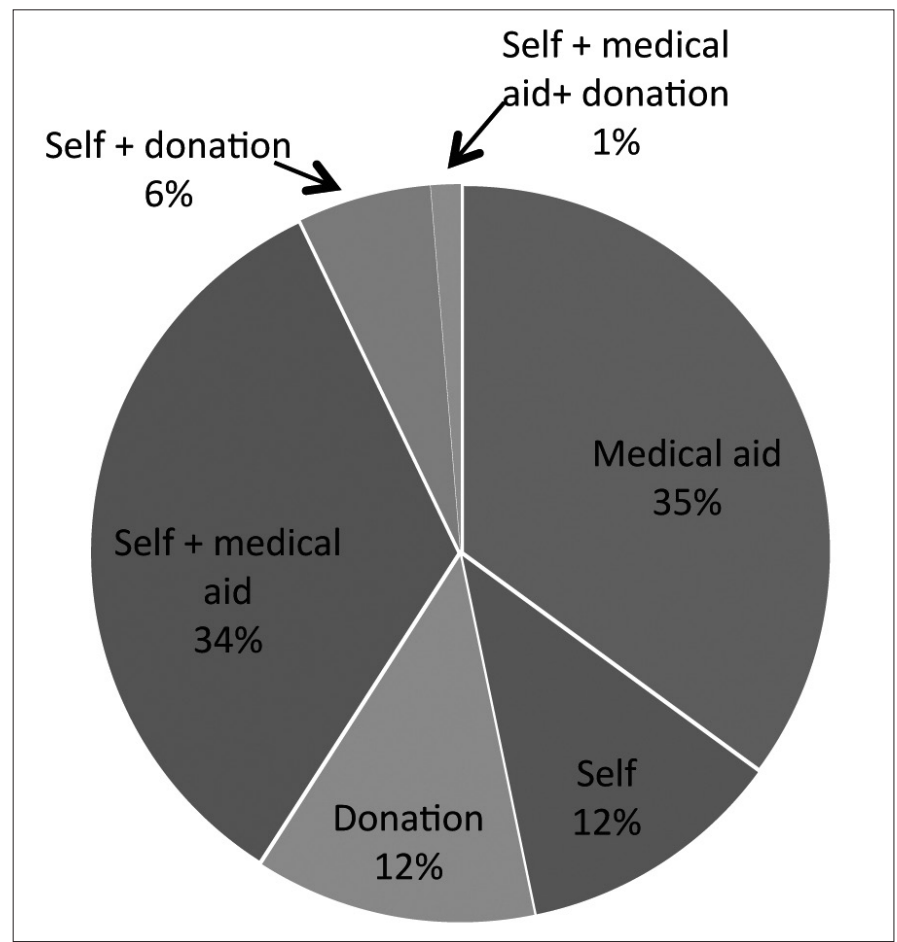

Fig. 2. Funding sources for cochlear implant system.

(range: 1 year to 14 years). Participants from one particular medical aid upgraded more regularly, as a result of their medical aid's funding policy. Many individuals on other medical aids, and all those not on medical aid, had to fund the upgrades themselves. Upgrades among the participants were less frequent than the current practice in the UK, where sound processors are upgraded free of charge on average every 4 - 5 years of use (S. Thomas, personal communication, 18 November 2010).

An increasing upgrading percentage, as well as multiple upgrades, was noted for those implanted the longest. All the participants implanted for more than 20 years had upgraded at least twice, with 2 individuals having upgraded 3 times, and 1 having upgraded 4 times. More than half the participants implanted for 15 - 20 years had upgraded twice. All the participants implanted for longer than 15 years had upgraded at least once. Most of the participants implanted for between 11 and 15 years had upgraded at least once, with more than a quarter upgrading twice. More than half the participants implanted for between 6 and 10 years had upgraded their sound processor, most of them once, and a small number twice. Most of the participants using their sound processor for less than 5 years had not upgraded.

\section{Batteries}

The monthly battery costs for the sound processor are shown in Appendix B. On average battery costs varied from R1 200 to R3 372 per year (R100 to R281 per month). The costs were influenced by the sound processor being used. Battery costs were generally lower for body-worn devices than for ear-level sound processors. Rechargeable batteries for the ear-level processors appeared to be more expensive than disposable batteries.

\section{Spare parts}

The analysis of spare parts included costs of ear-hooks, magnets, drying kits, snug-fits, cables and coils. Those implanted for more than 2 years had spent on average R276 per year on spares. There was, however, great individual variation, with some participants having no expenses, and others spending R916 per year. On average spares costs were greater for the children, especially during the 3 - 5-year period following implantation.

The average cost of cables and coils over 10 years was R2 838 for those participants who had had to replace them. These purchases occurred 
sporadically at different time intervals post implantation. Most participants only started replacing cables and coils from 4 years post implantation. Clustering of purchases occurred for a few individuals, especially some children.

\section{Repair costs}

The average repair cost of the sound processor was R3 000 per repair. The percentage of devices needing repair increased with longer duration of use, and especially after 6 years. Most participants had only had one repair in the 10-year time period reviewed. There were, however, a few notable exceptions, e.g. one individual, who had 4 repairs in 7 years 8 months of use.

\section{Travel and accommodation associated with visits to the implant unit}

Travel costs

The highest travel costs were noted for all participants during the first 2 years after implantation. On average those living within $50 \mathrm{~km}$ of Tygerberg Hospital spent R1 024 on travel in the first 2 years. Those living more than $1000 \mathrm{~km}$ away spent an average of R8 645 during the same time period.

\section{Accommodation costs}

One-third of the participants needed accommodation in order to attend implant-related appointments. There was a peak in accommodation costs during the first 2 years post implantation for those who lived more than $100 \mathrm{~km}$ from the unit. The average total accommodation cost for these participants was R3 390 for the first 2 years after implantation.

\section{Support services}

\section{Rehabilitation services for children}

The cost of rehabilitation services received by children was influenced by the frequency of therapy, length of time, number of therapies involved (single or multiple) and whether participants were seen at private or government facilities. Most participants (93\%) received speech-language therapy in the first 2 years following implantation, at an average cost of R7 070 per year.

As shown in Figure 3, a significant, though declining, percentage of children continued receiving speech-language therapy over $3-5$ years and $6-10$ years following implantation. The continued need for speech-language therapy for over $40 \%$ of the participants $6-10$ years post implantation may have been a reflection of the relatively late average age of implantation of the children in this study (4 years 5 months).

It is estimated that $40 \%$ of children will present with an identified disorder in addition to their hearing loss (Perigoe \& Perigoe, 2004; Picard, 2004), which will necessitate additional intervention. The children in this study were no exception. Figure 3 shows that, in addition to speech-language therapy, some of the children also required occupational therapy and physiotherapy. The number of children receiving these services was highest in the first 2 years after implantation, and declined over time.

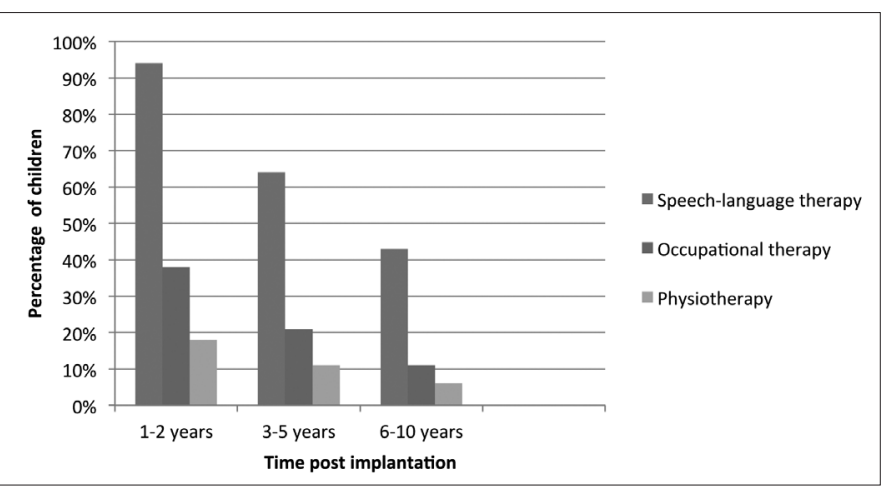

Fig. 3. Rehabilitation services received by children at different time intervals following implantation.

\section{Optional costs associated with implant use}

\section{Insurance}

Twenty-seven per cent of the participants had insured their sound processors. Some who wanted to insure their sound processors found the monthly premiums too costly to afford. Insurance premiums were on average R4 044 per year (R337 per month). They varied widely from R600 to R9 600 per year (R50 to R800 per month).

\section{Cost of hearing aid in the non-implanted ear}

One-third of the participants used a hearing aid in their nonimplanted ear. The cost of a hearing aid varied from R3 534 to R29 750. Half of these participants had purchased the hearing aid themselves and a quarter had received funding from their medical aid. Participants paid, on average, R31 a month for batteries. This was a fraction of the average monthly battery costs noted for the processor.

\section{Personal frequency modulated (FM) system}

The cost of an FM system varied from R9 964 to R21 750. Fifteen per cent of the participants had purchased an FM system. Most were purchased for children to use. Two-thirds of these participants paid for the device themselves. The rest were funded partially or in full by their medical aid.

\section{Advice from participants}

Participants were asked to provide advice about the costs involved in cochlear implantation to individuals who would potentially use a cochlear implant in the future. The following six themes were identified from the analysis of the participants' advice:

1. Need to budget carefully, plan and save for costs ( $46 \%$ of participants)

2. Importance of belonging to a medical aid that assisted with implant costs ( $44 \%$ of participants).

3. Use of multiple financial sources to purchase implant system (39\% of participants).

4. High cost of batteries for sound processor (23\% of participants).

5. Importance of insuring sound processor ( $17 \%$ of participants).

6. Meticulous care of the sound processor to increase its lifespan (16\% of participants).

\section{Limitations}

The findings of this study are based on information collected from half the individuals using a cochlear implant at one implanting unit in South Africa, which utilises only one make of implant system. Despite the relatively large sample size obtained, the findings may not be fully representative of the situation in the country as a whole. While these limitations should be heeded, the types of costs identified in the study are thought to hold relevance for all patients and implanting units in the country. The actual costs in the study are tied to a particular time and product and will need to be adjusted accordingly when applying the information in the future.

\section{Conclusion}

The findings of this study suggest that in order to meet the cost requirements of cochlear implantation in South Africa individuals using a cochlear implant need to make plans to meet the following short- and long-term costs:

- Obtain the funds for the initial purchase of the cochlear implant system (June 2010: R221 000).

- Pay for upgrading the sound processor (June 2010: R85 000) on average every 7 years. Alternatively every $10-15$ years once their sound processor becomes obsolete, or approximately every 3 - 5 years, if they want to stay abreast of the latest technology.

- Afford between R1 200 and R3 372 per year (R100 - R281 per month) for batteries.

- Purchase spare parts immediately as needed, and be prepared to spend on average R276 on spares per year (more for children).

- Pay sound processor repair cost of R3 000 .

- Afford the travel (and accommodation) expenses to access the implant unit for appointments. The costs are greatest in the first 2 years following implantation but remain ongoing. 
- Afford the programming of the sound processor. The number of appointments will be dependent on age at onset of hearing loss, age at implantation, and duration of use.

- Purchase and maintain a hearing aid for the non-implanted ear if indicated. These costs could range from R3 534 to R29 750.

- Insure the sound processor to avoid significant expenses should it become lost or stolen. Insurance could cost R600 - R9 600 per year (R50 - R800 per month).

- In addition parents or caretakers of children must be able to:

- Access and afford the rehabilitation required. The type, frequency and duration of required therapies are child-specific. The most likely is at least speech-language therapy (average R7 070 for 1 year).

- Purchase and maintain a personal FM system at an average cost of approximately R16 000 (range: R9 964 - R21 750; June 2010).

Individuals, who meet all the selection criteria and are considering a cochlear implant, as well as those already using one, should be informed about these expected costs, and the likely time periods post implantation they will be incurred. This knowledge will assist them in assessing the affordability of the intervention and planning for the costs to enable them to continue using their implant system successfully in the long term.

Clinicians engaged in candidate selection in South Africa will also benefit from the findings obtained. They must realistically consider an individual's ability to afford a cochlear implant, so that limited resources are not wasted and patients are not unintentionally financially burdened beyond their means and ability to achieve good outcomes.

Making a decision regarding an individual's or a family's ability to meet the potential long-term costs for candidates who may be able to meet the initial cost requirements may lead to an ethical dilemma for clinicians. The findings of this research could assist them in helping individuals consider their ability to meet the implementation costs of their intervention of choice more realistically.

\section{Implications for further research}

To expand the knowledge base of cost factors involved for individuals using a cochlear implant in South Africa, future studies could investigate: (i) the economic impact of bilateral implantation on individuals or their families; (ii) the economic impact on individuals or their families of the increasing trend towards younger implantation of congenitally deaf children; (iii) the effect of financial factors on non-use in the South African context; (iv) the indirect costs borne by individuals using a cochlear implant (e.g. time away from work to attend appointments and loss of earnings); and ( $v$ ) the cost of appropriate education for children using a cochlear implant in South Africa.

Acknowledgements. The authors thank all those individuals who took part in this study and Southern ENT Pty (Ltd) for access to their patient records. Thanks also to Professors Servaas Berger, Martin Kidd and Hannelie Nel at Stellenbosch University for their assistance in the data analysis, and Jenny Perold for assistance with the theme analysis.

\section{References}

Aronson, J. (1994). A pragmatic view of thematic analysis. The Qualitative Report, 2 (1). Retrieved from http://www. nova.edu/ssss/QR/BackIssues/QR2-1/aronson.html.

Bailey, D. M. (1997). Research for the health professional: A practical guide. Philadelphia: F. A. Davis.

Barton, G. R., Fortnum, H. M., Stacey, P. C., \& Summerfield, A. Q. (2006). Hearing impaired children in the
United Kingdom, III: Cochlear implantation \& the economic costs incurred by families. Ear \& Hearing, $27,563-57$

Blecher, M., Kollipara, A., De Jager, P., \& Zulu, N. (2011). Health financing. In A. Padarath \& R. English (Eds.), Sout African health review, South Africa: Health Systems Trust. Retrieved on 17 September 2012 from http:/www. hst-org.za/publications/south-african-health-review-2011.

Braun, V., \& Clark, V. (2006). Using thematic analysis in psychology. Qualitative Research in Psychology, 3(2), 77-101. ISSN 1478-0887 doi: 10.1191/1478088706qp063oa.

Carpenter, R. M. (2009). Correlates of sensorineural hearing loss and their effects on hearing aid benefit and implications for cochlear implantation. Ch. 5. In J. K. Niparko (Ed.) Cochlear implants: Principles and practices ( $2^{\text {nd }}$ ed., pp. 83-87). Philadelphia: Lippincott Williams \& Wilkins.

Cheng, A. K., Rubin, H. R., Powe, N. R., Mellon, N. K., Francis, H. W., \& Niparko, J. K. (2000). Cost-utility analysis of the cochlear implant in children. Journal of the American Medical Association, 284, 850-856. doi: 10.1001/ jama.284.7.850

Chute, P., \& Nevins, M. E. (2006). The winds of change: Fifteen years of cochlear implantation after FDA approval Ch.1. In School professionals working with children with cochlear implants (pp.1-15). San Diego: Plural Publishing Creative Research Systems. Survey design (2012). Retrieved on 18 September 2012 from www.surveysystem.com/ sdesign.htm

Doehring, D. G. (2003). Research strategies in human communication disorders ( $3^{\text {rd }}$ ed.). Austin, TX: PRO-ED, Inc

Drummond, A. (1996). Research methods for therapists. London: Chapman \& Hall.

Eisen, M. D. (2009). The history of cochlear implants. Ch. 6. In J. K. Niparko (Ed.), Cochlear implants: Principles and practices (2 ${ }^{\text {nd }}$ ed., pp. 89-93). Philadelphia: Lippincott Williams \& Wilkins.

Fitzpatrick, E., Duriex-Smith, A., Angus, D., Olds, J., Schramm, D., \& Whittingham, J. (2006). Economic evaluation of cochlear implants in children. Journal of Speech-Language Pathology and Audiology, 30, 215-223.

Glasscock, M. E. (2011). [Letter to the Editor]. Otology er Neurology. 32, 893-895.

Hegde, M. N. (2003). Clinical research in communicative disorders: Principles and strategies ( $3^{\text {rd }}$ ed.). Austin, TX: PROED, Inc.

Heffner, C. L., (2004). Descriptive statistics. Ch. 8. In Research methods. Retrieved on 17 September 2012 from http:/ allpsych.com/researchmethods/index.html.

Hutton, J., \& Politi, C. (1995). Cost-effectiveness of cochlear implantation of children: European study. Results of a modelling study in the United Kingdom, 16 April 1995. A report prepared for COCHLEAR AG. London: Battelle Medical Technology and Policy Research Centre.

Johnston, J.C., Durieux-Smith, A., Angus, D., O'Connor, A., \& Fitzpatrick, E. (2009). Bilateral paediatric cochlear implants: A critical review. International Journal of Audiology. 48, (9), 601-617. doi: 10.1080/14992020802665967

Khan, M. I. J., Mukhtar, N., Safeed, S. R., \& Ramsden, R. T. (2007). The Pakistan (Lahore) cochlear implant programme: issues relating to implantation in a developing country. The Journal of Laryngology \& Otology. 121, 745-750. doi: $10.1017 / 50022215107007463$

Lin, F. R., Niparko, J. K., \& Francis, H. W. (2009). Outcomes in cochlear implantation: Assessment of quality-oflife impact and economic evaluation of the benefits of the cochlear implant in relation to costs. Ch. 17. In J. K. Niparko (Ed.). Cochlear implants principles and practices ( $2^{\text {nd }}$ ed., pp. 229-243). Philadelphia: Lippincot Williams \& Wilkins.

McCormick, B. (2003). Preface. In B. McCormick \& S. Archbold (Eds.), Cochlear implants for young children ( $2^{\text {nd }}$ ed.) London \& Philadelphia: Whurr Publishers.

Molinier, L., Bocquet, H., Bongard, V., \& Frayesse, B. (2009). The economics of cochlear implant management in France: A multicentre analysis. European Journal of Health Economics 10, 347-355. doi: 10.1007/510198-009-0151-8

NIDCD. Cochlear implants. (2011). Retrieved on 24 February 2012 from http:/www.nidcd.nih.gov/health/hearing/ pages/coch.as.px

Niparko, J. K. (2009). Preface. In J. K. Niparko (Ed.), Cochlear implants: Principles and practices (2nd ed., p. IX). Philadelphia: Lippincott Williams \& Wilkins.

O'Neill, C. (2002). Where do we go from here in the economics of cochlear implantation? Ch. 10. In Cochlear implantation: cost creating or cost saving? Proceedings of a Conference on Health Technology Assessment (pp.121-122). Oxford: Hughes Associates.

Palmer, C. S., Niparko, J. K., Wyatt, J. R., Rothman, M., \& DeLissovoy, G. (1997). Cochlear implants: Health related quality of life and cost utility. Report prepared by MEDTAP International Inc. for Cochlear Corporation.

Perigoe, C. B., \& Perigoe, R. (Eds.) (2004). Foreword. The Volta Review: Multiple challenges - multiple solutions: children with hearing loss and special needs, 104(4) (monograph).

Peters, B. R., Wyss, J., \& Manrique, M. (2010). Worldwide trends in bilateral cochlear implantation. The Laryngoscope 120, S17-S45. doi: 10.1002/lary.20859

Picard, M. (2004). Children with permanent hearing loss and associated disabilities: revisiting current epidemiological data and causes of deafness. In C. B. Perigoe \& R. Perigoe (Eds.). The Volta Review: Multiple challenges - multiple solutions: children with hearing loss and special needs, 104(4), 211-214

Ramsden, J. D., Gordon, K., Aschendorff, A., Borucki, L., Bunne, M., Burdo, S., Garabedian, N., Grolman, W., Irving R., Lesinski-Schiedat, A., Loundon, N., Manrique, M., Martin, J., Raine, C., Wouters, J., \& Papsin, B. (2012) European bilateral pediatric cochlear implant forum consensus statement. Otology $\mho$ Neurotology, 33, 561-565. doi:10.1097/MAO.obo13e3182536ae2

Sach, T. (2002). Current knowledge and future directions: The economics of cochlear implantation. Ch. 4. In Cochlear implantation: Cost creating or cost saving? (pp. 35-70). Proceedings of a Conference on Health Technology Assessment. Oxford: Hughes Associates. doi: 10.1016/j.ijporl.2005.01.037

Sach, T. H., Whynes, D. K., Archbold, S. M., \& O’Donaghue, G. M. (2005). Estimating time and out of pocket costs incurred by families attending a paediatric cochlear implant programme. International Journal of Pediatric Otorhinolaryngology, 69(7), 929-936. doi: 10.1016/j.ijporl.2003.09.009

Sach, T. H., Whynes, D. K., O'Neill, C., O'Donaghue, G. M. \& Archbold, S. M. (2004).Willingness-to-pay for pediatric cochlear implantation. International Journal of Pediatric Otorhinolaryngology, 68, 91-99.

Statistics South Africa. P03022010-1pdf. Mid-year population estimates 2010 (2010). Retrieved on 16 Septembe 2012 from www.statssa.gov.za.

Stein, F., \& Cutler, S. K. (1996). Clinical research in allied and special education (3⿻ $3^{\text {rd }}$ ed.). San Diego: Singular Publishing Summerfield, A. Q Lovett, R. E. S. Bellenger H., \& Batten, G. (2010). Estimates of the cost-effectiveness of pediatric bilateral cochlear implantation. Ear \& Hearing, 13(5), 611-624.

Wagenfeld, D. J. H., \& Müller, A. M. U. (1994). Cochlear implants in the 3rd world. (pp. 422-430). In I. J. HochmairDesoyer \& E. J HochmairManz (Eds.). Advances in cochlear implants. Proceedings of the $3^{\text {rd }}$ International Cochlear Implant Conference, April 1993, Wien: Manz.

Wyatt, J. R., Niparko, J. K., Rothman, M .L., \& DeLissovoy, G. (1995). Cost effectiveness of the multichannel cochlear implant. The American Journal of Otology,16(1), 52-62. 


\section{Appendix A. Cochlear Implant Cost Questionnaire}

Instructions: Please complete the following questionnaire. The information is important, please try and fill in all the questions. If you don't know the exact data please give as close an approximation as you can.

For those who have two cochlear implants please answer all questions with regard to the first cochlear implant (CI).

Date completed:

Name of implant user:

Date of birth:

\section{QUESTION 1. DISTANCE TO THE COCHLEAR IMPLANT CENTRE}

1.1. How far did you live from the CI Centre while you were being evaluated for the cochlear implant? (Mark one block)

\begin{tabular}{|l|l|l|l|l|}
\hline Within $50 \mathrm{~km}$ & $51-100 \mathrm{~km}$ & $101-500 \mathrm{~km}$ & $501-1000 \mathrm{~km}$ & More than $1000 \mathrm{~km}$ \\
\hline & & & & \\
\hline
\end{tabular}

1.2. How far did you live from the CI centre during the first 2 years after receiving the implant? (Mark one block)

\begin{tabular}{|l|l|l|l|l|l|}
\hline No change & Within $50 \mathrm{~km}$ & $51-100 \mathrm{~km}$ & $101-500 \mathrm{~km}$ & $501-1000 \mathrm{~km}$ & More than $1000 \mathrm{~km}$ \\
\hline & & & & & \\
\end{tabular}

1.3. How far did you live from the CI centre during years 3 - 5 after receiving the implant? (Mark one block)

\begin{tabular}{|l|l|l|l|l|l|}
\hline No change & Within $50 \mathrm{~km}$ & $51-100 \mathrm{~km}$ & $101-500 \mathrm{~km}$ & $501-1000 \mathrm{~km}$ & More than $1000 \mathrm{~km}$ \\
\hline & & & & & \\
\end{tabular}

1.4. How far did you live from the CI centre during years $\mathbf{6}-\mathbf{1 0}$ after you received the implant? (Mark one block)

\begin{tabular}{|l|l|l|l|l|l|}
\hline No change & Within $50 \mathrm{~km}$ & $51-100 \mathrm{~km}$ & $101-500 \mathrm{~km}$ & $501-1000 \mathrm{~km}$ & More than $1000 \mathrm{~km}$ \\
\hline & & & & & \\
\end{tabular}

1.5. How far did you live from the CI centre during years 11 - 15 after the implant? (Mark one block)

\begin{tabular}{|l|l|l|l|l|l|}
\hline No change & Within $50 \mathrm{~km}$ & $51-100 \mathrm{~km}$ & $101-500 \mathrm{~km}$ & $501-1000 \mathrm{~km}$ & More than $1000 \mathrm{~km}$ \\
\hline & & & & & \\
\hline
\end{tabular}

1.6. How far did you live from the CI centre during years 15 - 20 after the implant? (Mark one block)

\begin{tabular}{|l|l|l|l|l|l|}
\hline No change & Within $50 \mathrm{~km}$ & $51-100 \mathrm{~km}$ & $101-500 \mathrm{~km}$ & $501-1000 \mathrm{~km}$ & More than $1000 \mathrm{~km}$ \\
\hline & & & & & \\
\hline
\end{tabular}

1.7. How far did you live from the CI centre from 20 years after the implant? (Mark one block)

\begin{tabular}{|l|l|l|l|l|l|}
\hline No change & Within $50 \mathrm{~km}$ & $51-100 \mathrm{~km}$ & $101-500 \mathrm{~km}$ & $501-1000 \mathrm{~km}$ & More than $1000 \mathrm{~km}$ \\
\hline & & & & & \\
\end{tabular}

1.8. Did you move to be closer to the CI centre?

Yes_ No

If YES please explain the reason(s):

1.9. Did you transfer to another cochlear implant program because of costs?

Yes No 


\section{QUESTION 2. TRANSPORT TO THE CI CENTRE}

2.1. How did you get to the CI centre at different points in time? (Mark all relevant blocks)

\begin{tabular}{|l|l|l|l|}
\hline Evaluation & Own transport & Public transport & Air travel +other \\
\hline First 2 years & Own transport & Public transport & Air travel +other \\
\hline Year 3 - 5 & Own transport & Public transport & Air travel +other \\
\hline Year 6 - 10 & Own transport & Public transport & Air travel + other \\
\hline Year 11 - 15 & Own transport & Public transport & Air travel +other \\
\hline Year 15 - 20 & Own transport & Public transport & Air travel +other \\
\hline Years 20 + & Own transport & Public transport & Air travel +other \\
\hline
\end{tabular}

2.2. What was the total transport cost during each time period? (Mark relevant blocks)

\begin{tabular}{|l|l|l|l|l|l|}
\hline Evaluation & R0 - R100 & R101 - R500 & R501 - R1 000 & R1 001 - R5 000 & More than R5 000 \\
\hline First 2 years & R0 - R100 & R101 - R500 & R501 - R1 000 & R1 001 - R5 000 & More than R5 000 \\
\hline Year 3 - 5 & R0 - R100 & R101 - R500 & R501 - R1 000 & R1 001 - R5 000 & More than R5 000 \\
\hline Year 6 - 10 & R0 - R100 & R101 - R500 & R501 - R1 000 & R1 001 - R5 000 & More than R5 000 \\
\hline Year 11 - 15 & R0 - R100 & R101 - R500 & R501 - R1 000 & R1 001 - R5 000 & More than R5 000 \\
\hline Year 15 - 20 & R0 - R100 & R101 - R500 & R501 - R1 000 & R1 001 - R5 000 & More than R5 000 \\
\hline Years 20 + & R0 - R100 & R101 - R500 & R501 - R1 000 & R1 001 - R5 000 & More than R5 000 \\
\hline
\end{tabular}

\section{QUESTION 3. ACCOMMODATION TO ATTEND APPOINTMENTS}

3.1. Did you ever have to stay away from home overnight as a result of attending appointments for your/your child's cochlear implant?

Yes

If YES, please indicate:

Did you stay with friends/relatives

Did you pay for accommodation or

If you paid for accommodation please complete the following table:

Indicate the total accommodation cost during each time period. (Mark relevant blocks)

\begin{tabular}{|c|c|c|c|c|c|}
\hline Evaluation & Less than R500 & R501 - R1 000 & R1 001 - R2 000 & R2 001 - R5 000 & More than R5 000 \\
\hline First 2 years & Less than R500 & R501 - R1 000 & R1 001 - R2 000 & R2 001 - R5 000 & More than R5 000 \\
\hline Year 3 - 5 & Less than R500 & R501 - R1 000 & R1 001 - R2 000 & R2 001 - R5 000 & More than R5 000 \\
\hline Year 6 - 10 & Less than R500 & R501 - R1 000 & R1 001 - R2 000 & R2 001 - R5 000 & More than R5 000 \\
\hline Year $11-15$ & Less than R500 & R501 - R1 000 & R1 001 - R2 000 & R2 001 - R5 000 & More than R5 000 \\
\hline Year 15 - 20 & Less than R500 & R501 - R1 000 & R1 001 - R2 000 & R2 001 - R5 000 & More than R5 000 \\
\hline Years 20+ & Less than R500 & R501 - R1 000 & R1 001 - R2 000 & R2 001 - R5 000 & More than R5 000 \\
\hline
\end{tabular}

\section{QUESTION 4. REPAIR OF SPEECH PROCESSOR}

4.1. How many times did your speech processor have to be repaired after its warranty expired?

\section{QUESTION 5. INSURANCE}

Is your speech processor insured?

Yes

If YES, please indicate:

Monthly premium: $\mathrm{R}$

How long has it been insured for?

\section{QUESTION 7. THE EAR WITHOUT THE IMPLANT}

Do you/your child use a hearing aid in the ear that is not implanted? Yes No

If YES, please indicate:

Cost: $\mathrm{R}$

How did you pay for it?

Self

Medical aid

Monthly cost of batteries:

\section{QUESTION 6. THE USE OF AN FM SYSTEM}

Have you bought an FM system to use with the CI?

Yes N No

If YES, please indicate:

Cost: R

How did you pay for it?

Self_ Medical aid 
QUESTION 8. ADVICE TO OTHERS

From your own experience with a cochlear implant, what advice would you give potential patients with regard to costs and planning for costs involved in obtaining and maintaining a cochlear implant?

If you/your child were/was implanted before the age of 13 years please continue to Question 9.

If you/your child were/was implanted after the age of 13 years you have now completed the questionnaire. Thank you very much for taking the time to complete the questionnaire.

\section{QUESTION 9. REHABILITATION SERVICES FOR CHILDREN WITH COCHLEAR IMPLANTS}

Please only answer this question if you/your child were/was implanted before the age of 13 years.

What extra costs did you have in the first year after implantation as a result of extra rehabilitation needed? (Mark relevant blocks)

\begin{tabular}{|c|c|c|c|}
\hline Therapy & How often? & Cost per year & How did you pay? \\
\hline \multirow[t]{3}{*}{ Speech therapy } & Daily & $\mathrm{R}$ & Self \\
\hline & Weekly & Can't remember & Medical aid \\
\hline & Monthly & & Included in school fees \\
\hline \multirow[t]{3}{*}{ Occupational therapy } & Daily & $\mathrm{R}$ & Self \\
\hline & Weekly & Can't remember & Medical aid \\
\hline & Monthly & & Included in school fees \\
\hline \multirow[t]{3}{*}{ Physiotherapy } & Daily & $\mathrm{R}$ & Self \\
\hline & Weekly & Can't remember & Medical aid \\
\hline & Monthly & & Included in school fees \\
\hline \multirow[t]{3}{*}{ Clinical psychology } & Daily & $\mathrm{R}$ & Self \\
\hline & Weekly & Can't remember & Medical aid \\
\hline & Monthly & & Included in school fees \\
\hline \multirow[t]{3}{*}{ Other: please specify } & Daily & $\mathrm{R}$ & Self \\
\hline & Weekly & Can't remember & Medical aid \\
\hline & Monthly & & Included in school fees \\
\hline
\end{tabular}

If you continued any of these services after the first year please complete the following table (mark relevant blocks)

\begin{tabular}{|c|c|c|c|}
\hline & Therapy (tick all relevant) & Estimate total cost of therapies & How did you pay? \\
\hline \multirow[t]{6}{*}{ Year 2 - 3 after CI } & None & $\mathrm{R}$ & Self \\
\hline & Speech therapy & Can't remember & Medical aid \\
\hline & Occupational therapy & & Included in school fees \\
\hline & Physiotherapy & & \\
\hline & Clinical psychology & & \\
\hline & Other: & & \\
\hline \multirow[t]{6}{*}{ Year 3 - 5 after CI } & None & $\mathrm{R}$ & Self \\
\hline & Speech therapy & Can't remember & Medical aid \\
\hline & Occupational therapy & & Included in school fees \\
\hline & Physiotherapy & & \\
\hline & Clinical psychology & & \\
\hline & Other: & & \\
\hline
\end{tabular}


QUESTION 9. REHABILITATION SERVICES FOR CHILDREN WITH COCHLEAR IMPLANTS

Please only answer this question if you/your child were/was implanted before the age of 13 years.

If you continued any of these services after the first year please complete the following table (mark relevant blocks)

\begin{tabular}{|c|c|c|c|}
\hline \multirow[t]{6}{*}{ Year 5 - 10 after $\mathrm{CI}$} & None & $\mathrm{R}$ & Self \\
\hline & Speech therapy & Can't remember & Medical aid \\
\hline & Occupational therapy & & Included in school fees \\
\hline & Physiotherapy & & \\
\hline & Clinical psychology & & \\
\hline & Other: & & \\
\hline
\end{tabular}

Thank you very much for taking the time to complete this questionnaire.

\section{Appendix B. Monthly battery costs for sound processor}

\begin{tabular}{|c|c|c|c|c|c|}
\hline Sound processor & $\begin{array}{l}\text { Percentage of } \\
\text { participants' current } \\
\text { sound processor }\end{array}$ & $\begin{array}{l}\text { Body-worn or } \\
\text { ear-level }\end{array}$ & Type of battery used & $\begin{array}{l}\text { Average monthly } \\
\text { battery cost (2010) }\end{array}$ & $\begin{array}{l}\text { Range of monthly } \\
\text { battery cost (2010) }\end{array}$ \\
\hline Spectra/SPrint ${ }^{\mathrm{Th}}$ & $1 \%$ & Body worn & Penlight & R100 & R50 - R150 \\
\hline ESPrit $^{\text {tm/ }} /$ ESPrit $^{\mathrm{m} m} 22$ & $1 \%$ & Ear-level & 2 disposables (size 675) & R125 & R100 - R150 \\
\hline ESPrit $^{\text {tw }} 3 \mathrm{G}(22 / 24)$ & $24 \%$ & Ear-level & 3 disposables (size 675) & R161 & R126 - R196 \\
\hline \multirow[t]{2}{*}{ Freedom $^{\circledast}$} & \multirow[t]{2}{*}{$64 \%$} & \multirow[t]{2}{*}{ Ear-level } & $\begin{array}{l}3 \text { disposables (size 675) } \\
\text { Or }\end{array}$ & $\mathrm{R} 180$ & \multirow[t]{3}{*}{ R110 - R146 } \\
\hline & & & $\begin{array}{l}\text { Lithium-ion (rechargeable), } \\
\text { based on } 2 \text { years' use } \\
\text { (charger }+2 \text { batteries included) }\end{array}$ & $\mathrm{R} 281$ & \\
\hline CP810 & $4 \%$ & Ear-level & $\begin{array}{l}\text { Lithium-ion (rechargeable), } \\
\text { based on } 2 \text { years' use (charger } \\
+2 \text { batteries included) }\end{array}$ & $\mathrm{R} 240$ & \\
\hline
\end{tabular}

\section{Correction}

In the article entitled 'Development of a music perception test for adult hearing-aid users' by Marinda Uys and Catherine van Dijk, which appeared on pp. 19 - 47 of the October 2011 issue of SAJCD (Vol. 58, issue 1), the logo of the University of Pretoria should have appeared on the Music Perception Evaluation answer sheet (Appendix A), the Music Perception Test answer sheet (Appendix D) and the Music Perception Test marking sheet (Appendix E). The online article was corrected on 26 January. The authors apologise to the university for this omission. 